\title{
Two New Maltol Glycosides and Cyanogenic Glycosides from Elsholtzia rugulosa Hemsl.
}

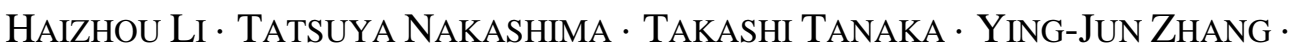

CHONG-REN YANG $\cdot$ ISAO KOUNO

HAIZHOU Li · TATSUYA NAKASHIMA · TAKASHi TANAKA* • ISAO KOUNO

Graduate School of Biomedical Sciences,

Nagasaki University, Bunkyo-Machi 1-14, Nagasaki 852-8521, Japan

E-mail: t-tanaka@nagasaki-u.ac.jp

Tel.:+81-95-819-2433

Fax.:+81-95-819-2477

YING-JUN ZHANG · CHONG-REN YANG

Laboratory of Phytochemistry, Kunming Institute of Botany, Chinese Academy of Sciences, Kunming 650204, P. R. China 
Abstract Two new maltol glycosides, maltol 6'-O- $\beta$-D-apiofuranosyl- $\beta$-D-glucopyranoside and maltol 6'-O-(5-O-p-coumaroyl)- $\beta$-D-apiofuranosyl- $\beta$-D-glucopyranoside, were isolated from Elsholtzia rugulosa Hemsl. along with eleven known compounds including prunasin and amygdalin. The structures were determined on the basis of spectroscopic and chemical evidence. This is the second example of isolation of cyanogenic glycosides from Lamiaceous plants.

Keywords Elsholtzia rugulosa $\cdot$ Lamiaceae $\cdot$ maltol glycoside $\cdot$ cyanogenic glycoside 


\section{Introduction}

Elsholtzia rugulosa Hemsl., which belongs to the Labiatae family, is distributed in the Yunnan, Sichuan and Guizhou provinces of China. It is one of the honey plants in this region, and has also been used as herbal tea or folk medicine for the treatment of colds, coughs, headaches, pharyngitis and fever [1]; however, the chemical constituents of this plant have not been clarified. This paper describes the isolation and structural determination of two new maltol glycosides together with eleven known compounds including two cyanogenic glycosides.

\section{Results and discussion}

An aqueous acetone extract of the air-dried plant was subjected to a combination of Diaion HP-20, Sephadex LH-20, silica gel and Chromatorex ODS column chromatography with various solvent systems to furnish 13 compounds. Known compounds maltol 3-O- $\beta$-D-glucoside [2], luteolin [3], luteolin 7-O- $\beta$-D-glucoside [4], luteolin 3'-O- $\beta$-D-glucuronide [5], quercetin 3-O- $\beta$-D-glucoside [6], tuberonic acid $\beta$-D-glucoside [7], benzyl alcohol $\beta$-D-glucoside [8], prunasin [9], amygdalin [10], caffeic acid [11], and rosmarinic acid [12] were identified based on comparison of their spectral data with those of authentic samples cited in the literature. This is only the second example of isolation of cyanogenic glycosides, prunasin and amygdalin, from Lamiaceous plants: the first case was from an Australian plant Clerodendrum grayi [13]. 
Compound 1 was obtained as a white amorphous powder and its molecular formula $\mathrm{C}_{17} \mathrm{H}_{24} \mathrm{O}_{12}$ was determined by ${ }^{13} \mathrm{C}$ NMR spectral analysis, MALDI-TOF-MS ( $\mathrm{m} / \mathrm{z} 443$, $\left.[\mathrm{M}+\mathrm{Na}]^{+}\right)$, and elemental analysis. The UV and IR spectral data of $\mathbf{1}$ showed the presence of an $\alpha, \beta$-unsaturated carbonyl group (255 nm and $1650 \mathrm{~cm}^{-1}$ ). The ${ }^{1} \mathrm{H}$ and

${ }^{13} \mathrm{C}$ NMR spectra of $\mathbf{1}$ resembled those of maltol 3-O- $\beta$-D-glucoside and showed signals due to a maltol group [ $\delta_{\mathrm{H}} 8.00(1 \mathrm{H}, \mathrm{d}, J=5.6 \mathrm{~Hz}, \mathrm{H}-6), 6.45(1 \mathrm{H}, \mathrm{d}, J=5.6 \mathrm{~Hz}, \mathrm{H}-5)$, and 2.45 (3H, s, H-7); $\delta_{\mathrm{C}} 164.6$ (C-2), 143.3 (C-3), 177.0 (C-4), 117.2 (C-5), 157.1 (C-6), and $15.9(\mathrm{C}-7)$ ]. However, two sugar anomeric proton signals appeared at $\delta_{\mathrm{H}} 4.78(\mathrm{~d}$, $\left.J=7.6 \mathrm{~Hz}, \mathrm{H}-1^{\prime}\right)$ and 4.95 (d, $\left.J=2.2 \mathrm{~Hz}, \mathrm{H}-1 "\right)$. The corresponding anomeric carbon resonances were observed at $\delta_{\mathrm{C}} 105.0$ and 110.7 , respectively, in the ${ }^{13} \mathrm{C}$ NMR spectrum. Chemical shift comparison of the remaining carbon signals (Table 1) with those of known 6-O-apiosyl glucoside suggested the presence of glucose and apiose in $\mathbf{1}$ [14]. Appearance of a set of doublets with geminal coupling attributable to an isolated methylene (apiose $\mathrm{H}-4 ")$ supported the presence of apiose. The relatively large $J$ values (7.6 Hz) of the anomeric proton at $\delta_{\mathrm{H}} 4.78$ indicated a $\beta$-configuration for the glucopyranosyl moiety. The ${ }^{13} \mathrm{C}$ NMR shift of the anomeric carbon of the apiofuranosyl unit at $\delta_{\mathrm{C}} 110.7$ also indicated a $\beta$-configuration [14]. The location of the $\beta$-apiose moiety at the C-6' of $\beta$-glucose was apparent from the large low field shift of the C-6' ( $\delta$ $68.8, \Delta \delta 6.3)$ compared with that of maltol 3-O- $\beta$-D-glucoside $(\delta 62.5)[2,14]$. The absolute configurations of the glucose and apiose were determined to be D-glucose and D-apiose by reversed-phase HPLC after conversion of the sugars to thiocarbamoyl-thiazolidine derivatives [15].

Compound 2 was obtained as a white amorphous powder and the ${ }^{1} \mathrm{H}$ and ${ }^{13} \mathrm{C}$ NMR spectra were closely related to those of $\mathbf{1}$, except for appearance of additional $9 \mathrm{sp}^{2}$ 
carbon signals arising from a p-coumaroyl ester group [ $\delta_{\mathrm{H}} 7.59$ (d, $\left.J=16.0 \mathrm{~Hz}, \mathrm{H}-7^{\prime \prime}\right)$, 6.30 (d, J=16.0 Hz, H-8"'), 7.41 (2H, d, J=8.5 Hz, H-2"', H-6"'), 6.76 (2H, d, J=8.5 Hz, H-3"', H-5"'); $\delta_{C} 127.0$ (C-1"'), 131.1 (C-2'", C-6"'), 116.8 (C-3"', C-5'"), 161.2 (C-4"'), 146.8 (C-7"'), 114.7 (C-8'"), 168.7 (C-9"')] [11]. The formula $\mathrm{C}_{26} \mathrm{H}_{30} \mathrm{O}_{14}$, which was determined by MALDI-TOF-MS ( $\left.\mathrm{m} / \mathrm{z} 589,[\mathrm{M}+\mathrm{Na}]^{+}\right)$and elemental analysis, is consistent with 2 being a $p$-coumaroyl ester of $\mathbf{1}$. The ${ }^{13} \mathrm{C}$ NMR spectrum showed sugar carbon signals similar to those of $\mathbf{1}$ except for the low field shift of apiose C-5"' $\left(\delta_{C}\right.$ 67.4, $\Delta \delta 1.9$ ). In addition, a large low field shift of the apiose $\mathrm{H}-5$ "' signal at $\delta 4.17$ (d, $J$ $=11.4 \mathrm{~Hz})$ and $4.21(\mathrm{~d}, J=11.4 \mathrm{~Hz})$ compared to those of $\mathbf{1}[\delta 3.54(2 \mathrm{H}, \mathrm{s})]$ unequivocally indicated the acylation of this position. Acid hydrolysis of $\mathbf{2}$ yielded p-coumaric acid and maltol along with D-apiose and D-glucose. Thus the structure of 2 was concluded to be maltol 6'-O-(5-O-p-coumaroyl)- $\beta$-D-apiofuranosyl - $\beta$-D-glucopyranoside.

This study revealed the presence of two cyanogenic glycosides, prunasin and amygdalin, and the total isolation yield was $0.08 \%$ from dry weight. Since Armeniacae semen (apricot kernel) which contains these compounds has been used for cough remedies in Europe and China, this result chemically supports the use of E. rugulosa for the treatment of colds and coughs in China. In addition, luteolin 3'-O- $\beta$-D-glucuronide [16-19] and rosmarinic acid [20-22] were found to be major phenolic constituents and these compounds are known to have anti-inflammatory activity. 


\section{Experimental}

\section{General}

UV spectra were obtained with a Jasco V-560 UV/Vis spectrophotometer and optical rotations were measured with a Jasco DIP-370 digital polarimeter. ${ }^{1} \mathrm{H}$ and ${ }^{13} \mathrm{C}$ NMR spectra were measured in $\mathrm{CD}_{3} \mathrm{OD}$ at $27^{\circ} \mathrm{C}$ with a Varian Unity plus 500 spectrometer operating at $500 \mathrm{MHz}$ for ${ }^{1} \mathrm{H}$ and $125 \mathrm{MHz}$ for ${ }^{13} \mathrm{C}$. Coupling constants are expressed in $\mathrm{Hz}$ and chemical shifts are given on a $\delta(\mathrm{ppm})$ scale. MS were recorded on a Voyager DE-PRO (Applied Biosystems) and JEOL JMS-700N spectrometer, 2,5-dihydroxybenzoic acid and glycerol were used as the matrix for MALDI-TOF-MS and FAB-MS measurements, respectively.

\section{Plant material}

The aerial parts of E. rugulosa Hemsl. were collected in Yunnan Province, China and identified by Professor Yang Chongren. A voucher specimen was deposited in the Kunming Institute of Botany, CAS, Kunming, China.

\section{Extraction and isolation}

The air-dried aerial parts of Elsholtzia rugulosa $(3.0 \mathrm{~kg})$ were extracted with 70\% aqueous acetone (10 l) at room temperature three times. The acetone was removed by evaporation under reduced pressure $\left(\mathrm{ca} .40^{\circ} \mathrm{C}\right)$, and the resulting dark green precipitates consisting mainly of chlorophylls and waxes were removed by filtration. The filtrate 
was concentrated to give an extract (170 g), which was directly subjected to Diaion HP-20 column chromatography $(8 \mathrm{~cm}$ i.d. $\times 45 \mathrm{~cm})$ with water containing increasing proportions of $\mathrm{MeOH}$ (20\% step-wise elution from 0 - $100 \%$ ) and finally with $50 \%$ aqueous acetone, and fractionated into 4 fractions. The first fraction (67.6 g) contained highly water soluble compounds and was mainly composed of sugars and the last fraction (19.6 g) contained non-polar substances including chlorophylls. Fraction 3 (21.3 g) was separated into two fractions by Diaion $\mathrm{HP}-20\left(0-100 \% \mathrm{MeOH}\right.$ in $\mathrm{H}_{2} \mathrm{O}$, 10\% step-wise elution) and the first fraction was combined with fraction 2 because these fractions contained similar compounds. Fraction 3-2 was subjected to Sephadex LH-20 column chromatography with $60 \% \mathrm{MeOH}$ to yield luteolin (76.3 mg). Fraction 2, after mixing with fraction 3-1, (35.0 g) was chromatographed over Diaion HP-20 (0 $100 \% \mathrm{MeOH}$ in $\mathrm{H}_{2} \mathrm{O}, 10 \%$ step-wise elution) to yield 4 fractions: 2-1 (2.0 g), 2-2 (17 g), 2-3 (3.7 g) and 2-4 (10.0 g). Fraction 2-1 was crystallized from water to give luteolin 3'-O- $\beta$-D-glucuronide (1.72 g). Fraction 2-2 was separated by a combination of column chromatography using Sephadex LH-20 (40 - 80 \% MeOH), Chromatorex ODS (0 $80 \% \mathrm{MeOH})$ and silica gel $60\left(\mathrm{CHCl}_{3}-\mathrm{MeOH}-\mathrm{H}_{2} \mathrm{O}, 80: 20: 2-70: 30: 5, \mathrm{v} / \mathrm{v} / \mathrm{v}\right)$ to furnish 1 (56.4 mg), 2 (44.2 mg), maltol 3-O- $\beta$-D-glucoside (52.2 mg), tuberonic acid $\beta$-D-glucoside (35.2 mg), benzyl alcohol $\beta$-D-glucoside (512.1 mg), prunasin (2.18 g), amygdalin (178.0 mg) and caffeic acid (60.4 mg). Fraction 2-3 was successively separated by Sephadex LH-20 (40 - $60 \% \mathrm{MeOH})$, Chromatorex ODS (0 - $80 \%$ $\mathrm{MeOH})$ and then silica gel $60\left(\mathrm{CHCl}_{3}-\mathrm{MeOH}-\mathrm{H}_{2} \mathrm{O}, 70: 30: 5\right)$ to yield luteolin 7-O- $\beta$-D-glucoside (50.0 mg) and quercetin 3-O- $\beta$-D-glucoside (84.0 mg). Chromatography of fraction 2-4 over Sephadex LH-20 (60 - 80 \% MeOH), 
Chromatorex ODS (20 - 60 \% MeOH) and Sephadex LH-20 (EtOH) afforded rosmarinic acid (874.5 $\mathrm{mg})$ and caffeic acid (67.5 mg).

\section{Maltol 6'-O- $\beta$-D-apiofuranosyl- $\beta$-D-glucopyranoside (1)}

White amorphous powder. $[\alpha]_{\mathrm{D}}^{25}-6.2^{\circ}\left(c\right.$ 0.7, MeOH). UV $\lambda_{\max }{ }^{\mathrm{EtOH}}(\log \varepsilon): 255$ (3.97). IR $v_{\max } \mathrm{cm}^{-1}:$ 3376, 1650. MALDI-TOF-MS m/z: $443[\mathrm{M}+\mathrm{Na}]^{+}$. Anal.Calcd for $\mathrm{C}_{17} \mathrm{H}_{24} \mathrm{O}_{12} \cdot 3 \mathrm{H}_{2} \mathrm{O}: \mathrm{C}, 43.04 ; \mathrm{H}, 6.37$. Found: $\mathrm{C}, 43.01 ; \mathrm{H}, 6.41 .{ }^{1} \mathrm{H}$ and ${ }^{13} \mathrm{C}$ NMR see Table 1.

\section{Maltol 6'-O-(5-O-p-coumaroyl)- $\beta$-D-apiofuranosyl- $\beta$-D-glucopyranoside (2)}

White amorphous powder. $[\alpha]_{\mathrm{D}}^{25}-81.5^{\circ}\left(c\right.$ 0.6, MeOH). UV $\lambda_{\max }{ }^{\mathrm{EtOH}}(\log \varepsilon): 258$ (4.09), 313 (4.35). IR $v_{\max } \mathrm{cm}^{-1}: 3402,1703,1647,1613$. MALDI-TOF-MS m/z: $589[\mathrm{M}+\mathrm{Na}]^{+}$. Anal.Calcd for $\mathrm{C}_{26} \mathrm{H}_{30} \mathrm{O}_{14} \cdot 4 \mathrm{H}_{2} \mathrm{O}$ : C, 48.90; H, 6.00. Found: C, 48.58; H, 6.12. ${ }^{1} \mathrm{H}$ and ${ }^{13} \mathrm{C}$ NMR see Table 1.

\section{Acid hydrolysis of 2}

A solution of $2(3 \mathrm{mg})$ in $1 \mathrm{M} \mathrm{HCl}(0.5 \mathrm{ml})$ was heated at $90-100{ }^{\circ} \mathrm{C}$ in a screw-capped vial for $5 \mathrm{~h}$. The mixture was partitioned with EtOAc $(0.5 \mathrm{ml})$ and the EtOAc layer was analyzed by HPLC [Cosmosil 5C 18 AR II $(250 \times 4.6$ mm i.d.); gradient elutions of $\mathrm{CH}_{3} \mathrm{CN}$ in $50 \mathrm{mM} \mathrm{H}_{3} \mathrm{PO}_{4}$ from 4-30\% in 39 min and 30-75\% in15 min; flow rate, $0.8 \mathrm{~mL} / \mathrm{min}$; detection with a Jasco MD-910 photodiode array detector]. 
The $t_{\mathrm{R}}$ and UV absorptions of the two peaks at $14.61 \mathrm{~min}$ and 29.55 min was coincided with those of maltol (UV $\lambda_{\max }: 223 \mathrm{~nm}$ ) and $p$-coumaric acid (UV $\lambda_{\max }: 310 \mathrm{~nm}$ ), respectively.

\section{Determination of aldose configuration}

A solution of $1(0.8 \mathrm{mg})$ in $1 \mathrm{M} \mathrm{HCl}(0.2 \mathrm{ml})$ was heated at $90-100{ }^{\circ} \mathrm{C}$ in a screw-capped vial for $5 \mathrm{~h}$. The mixture was neutralized by addition of Amberlite IRA400 ( $\mathrm{OH}^{-}$form $)$and filtered. The filtrate was dried in vacuo, dissolved in $0.2 \mathrm{ml}$ of pyridine containing L-cysteine methyl ester $(10 \mathrm{mg} / \mathrm{ml})$ and reacted at $60{ }^{\circ} \mathrm{C}$ for $1 \mathrm{~h}$. To this mixture a solution $(0.2 \mathrm{ml})$ of $o$-torylisothiocyanate in pyridine $(10 \mathrm{mg} / \mathrm{ml})$ was added and it was heated at $60{ }^{\circ} \mathrm{C}$ for $1 \mathrm{~h}$. The final mixture was directly analyzed by HPLC [Cosmosil 5C 18 AR II (250 × 4.6 mm i.d., Nacalai Tesque Inc.); $25 \% \mathrm{CH}_{3} \mathrm{CN}$ in $50 \mathrm{mM} \mathrm{H}_{3} \mathrm{PO}_{4}$; flow rate, $0.8 \mathrm{~mL} / \mathrm{min}$; detection, $250 \mathrm{~nm}$ ]. The $t_{\mathrm{R}}$ of the two peaks at 17.48 and 28.57 min coincided with those of D-glucose and D-apiose, respectively. The standard samples of D- and L-apiose were synthesized from L- and D-ribose, respectively [23]. The aqueous layer remaining after partition with EtOAc on the acid hydrolysis of $\mathbf{2}$ was treated in the manner similar to that described for $\mathbf{1}$ and the HPLC analysis showed the presence of D-glucose and D-apiose. 


\section{Acknowledgements}

The authors are grateful to Mr. K. Inada and Mr. N. Yamaguchi (Nagasaki University)

for NMR and MS measurements. This work was supported by a Grant-in-aid for

Scientific Research No. 18510189 from the Japan Society for the Promotion of Science.

\section{References}

1. Jiangshu New College of Medicine (1985) In: The Dictionary of Chinese Medicine, Shanghai, Shanghai Press of Science and Technology, p 2132

2. Tanaka N, Sakai H, Murakami T, Saiki Y, Chen CM, Iitaka Y (1986) Chemical and chemotaxonomic studies on pterophyten. LXII. Chemical studies on the substance from Arachniodes maximowiczii Ohwi. Chem Pharm Bull 34:1015-1022

3. Ulubelen A, Doguc T (1974) Flavonoid compounds from the flowers of Genista lydia. Planta Med 25:39-42

4. Kikuchi M, Yamauchi Y (1985) Studies on the constituents of Osmanthus species. IV. On the components of the leaves of Osmanthus fortunei Carr. Yakugaku Zasshi 105:542-546

5. Ulubelen A, Miski M, Neuman P, Mabry TJ (1979) Flavonoids of Salvia tomentosa (Labiatae). J Nat Prod 42:261-263

6. Markham KR, Ternai B, Stanley R, Geiger H, Mabry TJ (1978) Carbon-13 NMR studies of flavonoids-III : Naturally occurring flavonoid glycosides and their acylated derivatives. Tetrahedron 34:1389-1397

7. Ueda M, Okazaki M, Ueda K, Yamamura S (2000) Leaf-Closing Substance of Albizzia julibrissin Durazz. Tetrahedron 56:8101-8105

8. Miyase T, Ueno A, Takizawa N (1987) Studies on the glycosides of Epimedium grandiflorum Morr. var. thunbergianum (Miq.) Nakai. I. Chem Pharm Bull 35:1109-1117 
9. Ling SK, Tanaka T, Kouno I (2002) New cyanogenic and alkyl glycoside constituents from Phyllagathis rotundifolia. J Nat Prod 65:131-135

10. Tanaka T, Zhang H, Jiang ZH, Kouno I (1997) Relationship between hydrophobicity and structure of hydrolysable tannins, and association of tannins with crude drug constituents in aqueous solution. Chem Pharm Bull 45:1891-1897

11. Jiang ZH, Hirose Y, Iwata H, Sakamoto S, Tanaka T, Kouno I (2001) Caffeoyl, coumaroyl, galloyl, and hexahydroxydiphenoyl glucoses from Balanophora japonica. Chem Pharm Bull 49:887-892

12. Tanaka T, Morimoto S, Nonaka G, Nishioka I, Yokozawa T, Chung HY, Oura H (1989) Magnesium and ammonium-potassium lithospermates B, the active principles having a uremia-preventive effect from Salvia miltiorrhiza. Chem Pharm Bull 37:340-344

13. Miller RE, McConville MJ, Woodrow IE (2006) Cyanogenic glycosides from the rare Australian endemic rainforest tree Clerodendrum grayi (xLamiaceae). Phytochemistry 67:43-51

14. Jiang ZH, Tanaka T, Kouno I (1999) New phenylpropanoid glycosides from the fruits of Illicium anisatum. Chem Pharm Bull 47:421-422

15. Tanaka T, Nakashima T, Ueda T, Tomii T, Kouno I (2007) Chem Pharm Bull, 55:899-901.

16. Gutierrez-Venegas G, Kawasaki-Cardenas P, Rita Arroyo-Cruz S, Maldonado-Frias S (2006) Luteolin inhibits lipopolysaccharide actions on human gingival fibroblasts. Eur J Pharmacol 541:95-105

17. Kim JS, Lee HJ, Lee MH, Kim J, Jin C, Ryu JH (2006) Luteolin inhibits LPS-stimulated inducible nitric oxide synthase expression in BV-2 microglial cells. Planta Med 72:65—68

18. Odontuya G, Hoult JRS, Houghton PJ (2005) Structure-activity relationship for antiinflammatory effect of luteolin and its derived glycosides. Phytother Res 19: 782-786

19. Hougee S, Sanders A, Faber J, Graus YMF, van den Berg WB, Garssen J, Smit HF, Hoijer MA (2005) Decreased pro-inflammatory cytokine production by LPS-stimulated PBMC upon in vitro incubation with the 
flavonoids apigenin, luteolin or chrysin, due to selective elimination of monocytes/macrophages. Biochem Pharmacol 69:241-248

20. Englberger W, Hadding U, Etschenberg E, Graf E, Leyck S, Winkelmann J, Parnham MJ (1988) Rosmarinic acid: a new inhibitor of complement C3-convertase with anti-inflammatory activity. Int J Immunopharmac 10:729-737

21. Osakabe N, Yasuda A, Natsume M, Yoshikawa T (2004) Rosmarinic acid inhibits epidermal inflammatory responses: anticarcinogenic effect of Perilla frutescens extract in the murine two-stage skin model.

Carcinogenesis 25:549—557

22. Osakabe N, Takano H, Sanbongi C, Yasuda A, Yanagisawa R, Inoue K, Yoshikawa T (2004) Anti-inflammatory and anti-allergic effect of rosmarinic acid (RA); inhibition of seasonal allergic rhinoconjunctivitis (SAR) and its mechanism. BioFactors 21:127-131

23. Yun M, Moon HR, Kim HO, Choi WJ, Kim Y, Park CS, Jeong, LS (2005) A highly efficient synthesis of unnatural L-sugars from D-ribose. Tetrahedron Lett 46:5903-5905 
Figure Legend

Figure 1 Structures of compounds $\mathbf{1}$ and $\mathbf{2}$ 


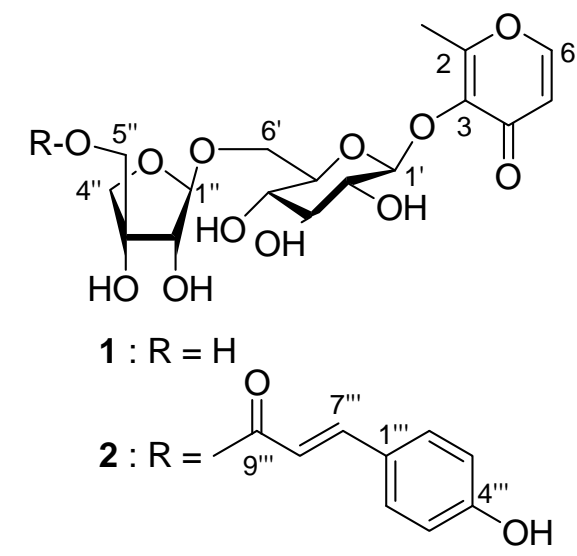

Figure 1 
Table $1 .{ }^{1} \mathrm{H}-$ and ${ }^{13} \mathrm{C}-\mathrm{NMR}$ data for compounds 1 and $2\left({ }^{1} \mathrm{H} ; 500 \mathrm{MHz},{ }^{13} \mathrm{C} ; 125 \mathrm{MHz}, \mathrm{CD}_{3} \mathrm{OD}\right)$

\begin{tabular}{|c|c|c|c|c|}
\hline & \multicolumn{2}{|r|}{$\mathbf{1}$} & \multicolumn{2}{|r|}{2} \\
\hline & ${ }^{13} \mathrm{C}$ & ${ }^{1} \mathrm{H}$ & ${ }^{13} \mathrm{C}$ & ${ }^{1} \mathrm{H}$ \\
\hline \multicolumn{5}{|l|}{ maltol } \\
\hline 2 & 164.6 & & 164.4 & \\
\hline 3 & 143.3 & & 143.3 & \\
\hline 4 & 177.0 & & 176.9 & \\
\hline 5 & 117.2 & $6.45(\mathrm{~d}, 5.6)$ & 117.2 & $6.38(d, 5.6)$ \\
\hline 6 & 157.1 & $8.00(d, 5.6)$ & 157.0 & $7.89(\mathrm{~d}, 5.6)$ \\
\hline 7 & 15.9 & $2.45(\mathrm{~s})$ & 15.9 & $2.39(\mathrm{~s})$ \\
\hline \multicolumn{5}{|l|}{ D-glucose } \\
\hline $1^{\prime}$ & 105.0 & $4.78(\mathrm{~d}, 7.6)$ & 105.2 & $4.72(\mathrm{~d}, 7.6)$ \\
\hline $2^{\prime}$ & 74.9 & $3.27-3.45$ (m) & 74.9 & $3.25-3.40(\mathrm{~m})$ \\
\hline $3^{\prime}$ & 77.9 & $3.27-3.45(\mathrm{~m})$ & 78.4 & $3.25-3.40(\mathrm{~m})$ \\
\hline $4^{\prime}$ & 71.3 & $3.27-3.45(\mathrm{~m})$ & 71.3 & $3.25-3.40(\mathrm{~m})$ \\
\hline $5^{\prime}$ & 77.4 & $3.27-3.45(\mathrm{~m})$ & 77.4 & $3.25-3.40(\mathrm{~m})$ \\
\hline \multirow[t]{2}{*}{$6^{\prime}$} & 68.5 & 3.94 (dd, 2.0, 11.2) & 68.5 & $3.93(\mathrm{~d}, 11.2)$ \\
\hline & & 3.60 (dd, 6.1, 11.2) & & 3.57 (dd, 6.0, 11.2) \\
\hline \multicolumn{5}{|l|}{ D-apiose } \\
\hline 1" & 110.7 & $4.95(\mathrm{~d}, 2.2)$ & 110.4 & $4.94(\mathrm{~d}, 2.2)$ \\
\hline 2" & 77.8 & 3.84 (d, 2.2) & 77.9 & 3.92 (d, 2.2) \\
\hline 3" & 80.4 & & 78.9 & \\
\hline $4 "$ & 75.3 & $3.89(\mathrm{~d}, 9.5)$ & 75.3 & $3.90(\mathrm{~d}, 9.8)$ \\
\hline & & $3.73(\mathrm{~d}, 9.5)$ & & $3.78(\mathrm{~d}, 9.8)$ \\
\hline 5" & 65.5 & $3.54(2 \mathrm{H}, \mathrm{s})$ & 67.4 & $4.21(\mathrm{~d}, 11.4)$ \\
\hline & & & & $4.17(\mathrm{~d}, 11.4)$ \\
\hline \multicolumn{5}{|l|}{$p$-coumaroyl group } \\
\hline $1 " '$ & & & 127.0 & \\
\hline 2"', 6"' & & & 131.1 & $7.41(\mathrm{~d}, 8.5)$ \\
\hline 3"', 5"' & & & 116.8 & $6.76(\mathrm{~d}, 8.5)$ \\
\hline 4"' & & & 161.2 & \\
\hline $7^{\prime \prime}$ & & & 146.8 & $7.59(\mathrm{~d}, 16.0)$ \\
\hline 8"' & & & 114.7 & $6.30(\mathrm{~d}, 16.0)$ \\
\hline 9"' & & & 168.7 & \\
\hline
\end{tabular}

Coupling constants $(J$ in $\mathrm{Hz})$ are given in parentheses 